\title{
Megalithic Constructions Discovered in the Azores, Portugal
}

\author{
António Félix Rodrigues \\ Department of Agricultural and Environmental Sciences, University of the Azores, Angra do Heroísmo, Portugal \\ Email: felix@uac.pt
}

Received 13 February 2015; accepted 30 March 2015; published 31 March 2015

Copyright (C) 2015 by author and Scientific Research Publishing Inc.

This work is licensed under the Creative Commons Attribution International License (CC BY).

http://creativecommons.org/licenses/by/4.0/

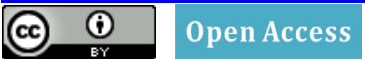

\section{Abstract}

The oldest cave art known is of prehistoric origin, dating back to approximately 40,000 years ago in both Asia and Europe. The megalithic constructions in Western Europe and the Mediterranean Region took place mainly in the Neolithic and continued until the Chalcolithic and Bronze Age. The Azores Islands did not seem to have been occupied before the arrival of the Portuguese navigators in the XVth century. Because of that, it was not expected that megalithic structures would be found, or structures that resembled megalithic tombs and rock art in the Azores Islands, geographically located in the Center of the North Atlantic, at $1500 \mathrm{~km}$ west of Lisbon (Portugal) and about 1900 $\mathrm{km}$ southeast of Newfoundland (Canada). These findings seem to be, historically, a paradox. In a first moment, an oral presentation was made about these findings by the author at the 16th Annual Mediterranean Studies Association Congress, and after that, a field trip took place with the archeologists present at the stated Congress. The perplexity was the dominant conduct of the guests, and some hypotheses that certain archaeologists mentioned were evolved versions which had not been empirically corroborated. Afterwards, new findings were registered at Grota do Medo site, helping to make clear that larger stones had been used to construct structures or monuments. The rock art surrounding the megalithic constructions in the Azores also has similarities with those found in Europe. If these findings belong to the Bronze Age or Iron Age, it can reopen new scientific questions about ancient mid-Atlantic crossings. The present article tries to establish ties among the megalith constructions found in the Azores with those known in Europe.

\section{Keywords}

Megalithic Constructions, Azores Islands, Rock Art, Bronze Age or Iron Age Hypothesis

\section{Introduction}

The author has surveyed a little known area of Terceira Island in the Azores, Portugal, and brought to light a 
wide-ranging work on structures and rock art with an uncertain chronology, the use of which is not reported in the Azores Islands' historiography. By studying and classifying the Azorean construction's and rock art, and making global parallels, the structures and rock art presented showed an unexpected evolving trend—resembling the European megalithic culture, but the large collection of writings about this specific subject, specially about the megalithic art from the Neolithic period, was fairly enigmatic (Brennan, 1983; O'Sullivan, 1988; Garcia et al., 1999).

Due to the uncertain chronology of the Terceira Island's megalithic constructions, it can be assumed that a megalith is a large stone (as the Greek meaning of the word) that has been used to construct a structure or monument, either alone or together with other stones. But the term is also applied all-inclusively to the architecture of megalithic structures, to the sculptural and other designed features associated to them, and to rock art related to these structures (Johnson, 1908). It is hard, at the moment, to be more precise when using this word for the structures with large stones or for the rock art found in the Terceira Island, due to the absence of dated artifacts.

The construction of megalithic structures took place mainly in the Neolithic (though earlier Mesolithic examples were known) and continued until the Chalcolithic and Bronze Age (Contu, 2000).

Assuming that even scientific knowledge is only conjectural, and that the result is a successful speculation, the construction of theoretical ideas is based on empirical data. Assuming that even a Neolithic's or Bronze Age provenance from the "ruins" found at Terceira Island-Azores could fascinate researchers, at the moment it was a conjecture, because the island inhabitants, in the historical times, could have created similar constructions brought by other kinds of necessities or by the different environment that they found when they arrived to the Azores Islands, and could have used similar materials without an effective connection among the distinct European Neolithic's places.

It is not completely impossible to establish some associations between a hypothetical ancient human occupation of the Terceira Island and the Western European megalithic culture. There is a large body of research on prehistorical marine journeys, for example, Clark (2004), Cunliffe (2009) or Van de Noort (2009), which supports the idea of trade and cultural change by sea, from an early time, particularly between northern and western France, which has been maintained over several centuries.

Exploring the traveling ritual in prehistoric Europe, Van de Noort (2009: p. 159) states, "this is surprising when one considers that in a prehistoric, a-literate society, travelling offers the only opportunity to increase knowledge and understanding once the social memory of one's locale has been exhausted, and it can thus lead to the introduction of new materials and ideas which can in turn result in innovations and cultural change".

In September 1992, archaeologists discovered the perfectly preserved remains of a complex sewn-plank boat of middle Bronze Age date (now dated to 1550 cal BC), buried deep below the streets of modern day Dover in SE England (Clark, 2004). Studying the landscape context of the early Bronze Age boats, especially Kilnsea (discovered on the beach at Kilnsea in East Yorkshire in 1996), Caldicot 1 (discovered at North Ferriby in the Haltemprice area of the East Riding of Yorkshire), the Dover boat, and the deposition of exotic goods, Clark (2004) mentions the presence of artifacts such as a jade axe, or artifacts such as wagon parts and wheels near track ways. In this context the obsidian also seems to be an exotic good in some Bronze Age societies.

Obsidian distribution patterns in the Epi-Palaeolithic and earliest Neolithic had simply documented the dissemination of source-specific products across space (see Cauvin et al., 1998) which led Carter (2014) to argue that everyone using the same raw materials was somehow linked. He conceived that different people, at the same time, could have looked for, exchanged and worked obsidian in many different ways.

Cauvin (2000) says that the idea of "Neolithisation" being articulated, via pre-existing obsidian exchange systems, is not new, but it is hard to try and reconstruct more specifically the inter-community networks through which such new practices may have spread.

The "Santa Bárbara" stratovolcano in Terceira Island is truncated by a collapse calderas complex, being almost filled-up by trachytic domes. On its flanks there are several volcano-tectonic lineaments of coulées and domes, often with obsidian.

If Terceira Island is directly linked to the ritual association of travel by sea, especially in the ritual of travel in prehistoric Europe, it is probably connected to the ancestors, as Carter (2014) argues.

Needham (1985) says, for the Middle Bronze Age, at the South East England, that the development of this area certainly seems to have personified a changing attitude towards the sea, and this must be related sequentially to an increased sense of purpose for crossing the sea on a more regular basis.

At the moment, no studies are able to propose any kind of connections between the megalithic structures dis- 
covered in Terceira Island and similar ones in the Western Europe. We can only make some conjectures.

\section{Structures Similar to Passage Tombs at Grota do Medo Site}

Two structures, discovered at Grota do Medo site, are similar to Passage Tombs, or as in Spanish, tumbas de corredor, one of them located above the other, $10 \mathrm{~m}$ high from floor, where the entrance pointing in to the Southeast direction (see Figure 1 and Figure 2).

The passage tombs are found from the western seaboard of Scotland to South of Spain and forms part of an Atlantic façade coastal distribution that is currently attested by funerary monuments (in the form of small closed polygonal megalithic chambers and simple passage tombs). These megalithic constructions constitute the earli-

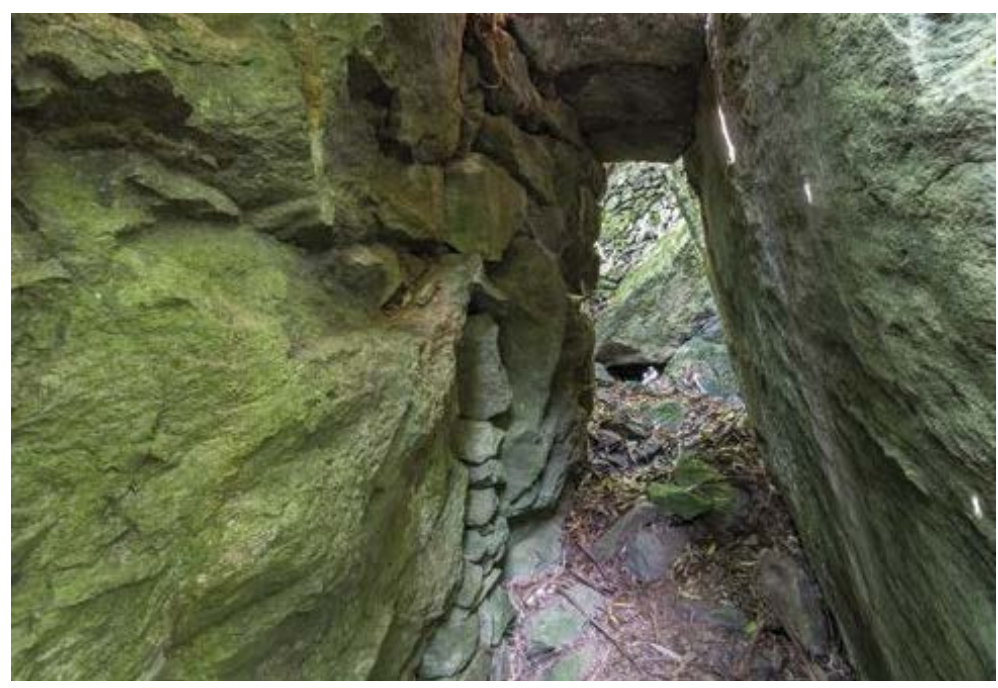

Figure 1. Megalithic construction with similarities to the European Passage Tombs at Grota do Medo site.

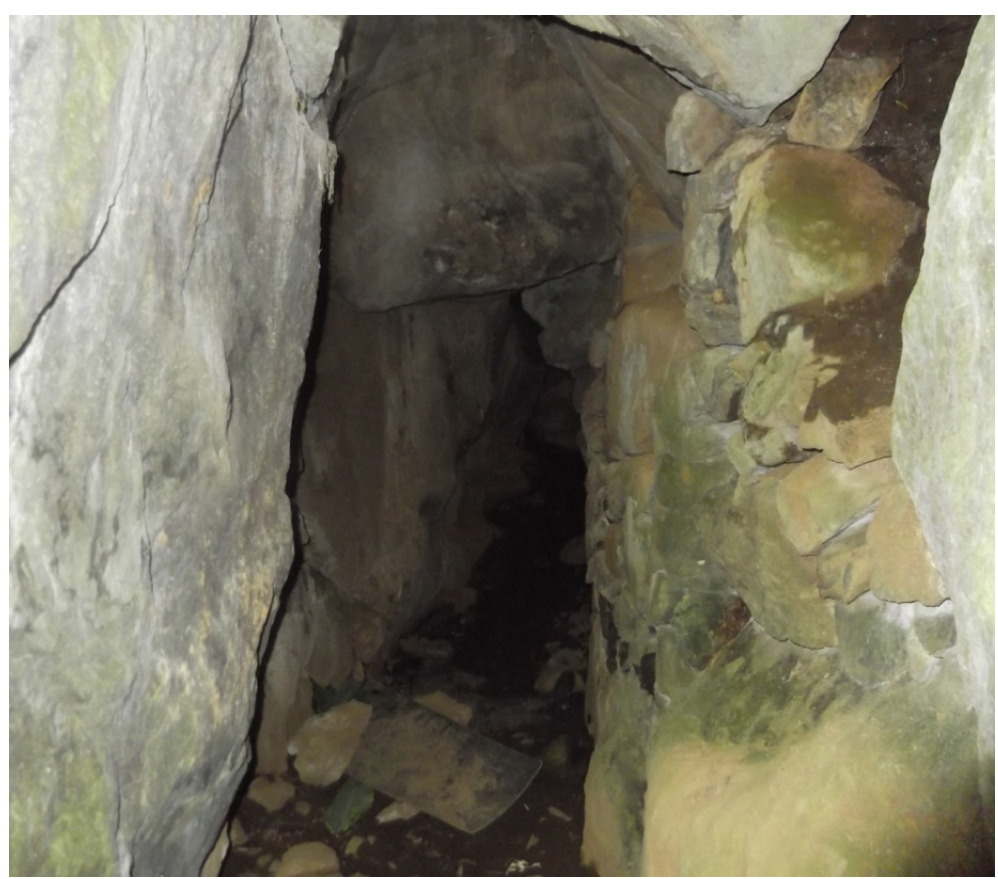

Figure 2. Structure similar to a Passage Grave or a Passage Tomb, made of larger stones and with a kind of burial chamber covered by earth and stone. 
est funerary monuments and the earliest pottery in Britain and Ireland, and the origin of both resides in the Morbihan region of South-Eastern Brittany (Sheridan, 2010).

Also Ó Nualláin \& De Valera (1961) attest that only passage tombs appear to have widespread distribution throughout Europe.

The megalithic structure captured in Figure 1, found at Terceira Island, is alike a passage-grave that runs back into the mound about $4 \mathrm{~m}$. At the end of the corridor it is found a space comparable to a collapsed burial chamber larger circular one, with a $3 \mathrm{~m}$ in diameter.

According to Knight (2011), several later passage tombs were constructed at the tops of hills or mountains, signifying that their creators planned them to be seen from a great distance. The same could be said about the structures that resembles megalithic constructions in the Azores. Many of them where build in the higher point of Pico do Espigão, a hill that dominates the greater part of the Terceira Island's landscape and seascape.

Under the early mentioned megalithic structure was found another one (Figure 2) that, once more, resembles another Passage Tomb structure, nevertheless bigger than the first one. The corridor has $7.5 \mathrm{~m}$ long with $1.5 \mathrm{~m}$ larger.

Stone walls, at left and right sides, with $1.5 \mathrm{~m}$ height, made of worked block stones, support big stones (with more than 2 tons) with an inclination of $57^{\circ}$. At the ceiling, three big stones form a pyramided end shape, which are physically important for the structure's equilibrium. The corridor ends in a kind of circular burial chamber, with $2.5 \mathrm{~m}$ larger and $1.5 \mathrm{~m}$ height. The opening orientation of this corridor is to the North.

The building of passage tombs was normally carried out with megaliths and smaller stones (Knight, 2011) like it were found in Terceira Island. They usually date from the Neolithic Age (Knight, 2011).

Cunliffe (2001), in his book "Facing the Ocean", focuses on the western rim of Europe (the Atlantic façade) an area stretching from the Straits of Gibraltar to the Isles of Shetland, showing how original and inventive these societies were, and how they preserved their own distinctive identities often over long extents of time. In his book, the author covered the period from the Mesolithic hunter-gatherers, c. $8000 \mathrm{BC}$, to the sea journeys of discovery c. AD 1500. According to this author, the Atlantic Bronze Age is a cultural complex of the Bronze Age period of approximately 1300-700 BC, that marked the economic and cultural exchange between Portugal, Spain, France, and the British Isles.

The distance by sea between the South of Spain to the British Isles is almost the same distance between Portugal (mainland) and the Terceira Island (near $1500 \mathrm{~km}$ ). Taking this in account, it is not a question of distance travel by sea in the Bronze Age that made impossible to arrive to the Azores in these times, but a question of direction chosen.

It is not possible, at the moment, to answer the question: "The communities from the Atlantic façade arrived to the Azores in the Bronze Age ?", because we have only similarities between megalithic structures amongst the two places and none pottery or artifacts dating from this period, but it must be noted that no archaeological digging or probing was made in the site.

\section{Worked Stones and Their Metaphorical Association with Water}

In the Grota do Medo site at Terceira Island; it seems to be present a metaphorical association between water and stone, with some parallels to the Neolithic places of the Ireland. Dozens of bowls where found in this place, with a larger number of them at the capstones of the megalithic constructions or monolithic blocks near the cliffs. Despite the perceived bowls erosion, even now, when it rains, they stay full of water that runs down to the cliffs or to the entrance of the megalithic constructions.

Bradley (1997) has been noted that rock art sites from Bronze and Iron Age are also frequently located in relation to bodies of water. For example, at Trellyffaint in Southwest Wales there are a number of cup-marks engraved on the surface of the capstone (Barker, 1992). Likewise, the site of Bachwen in North Wales has bowls on the capstone (Daniel, 1950) with similarities to those ones found at Terceira Island.

It is also interesting that many of the Bargrennan monuments in southwest Scotland incorporate natural cupmarks into their structures, such as the large natural hollows in the capstone at Cairnderry (Cummings, 2001). The large bowls incorporated in the capstones of megaliths at Terceira Island are clearly man made (see Figure $3)$.

Fowler \& Cummings (2003) suggest an association in the Neolithic between water and stone that was created through topographic and visual references to the sea, rivers, and watercourses, as well as mountains and outcrops. 


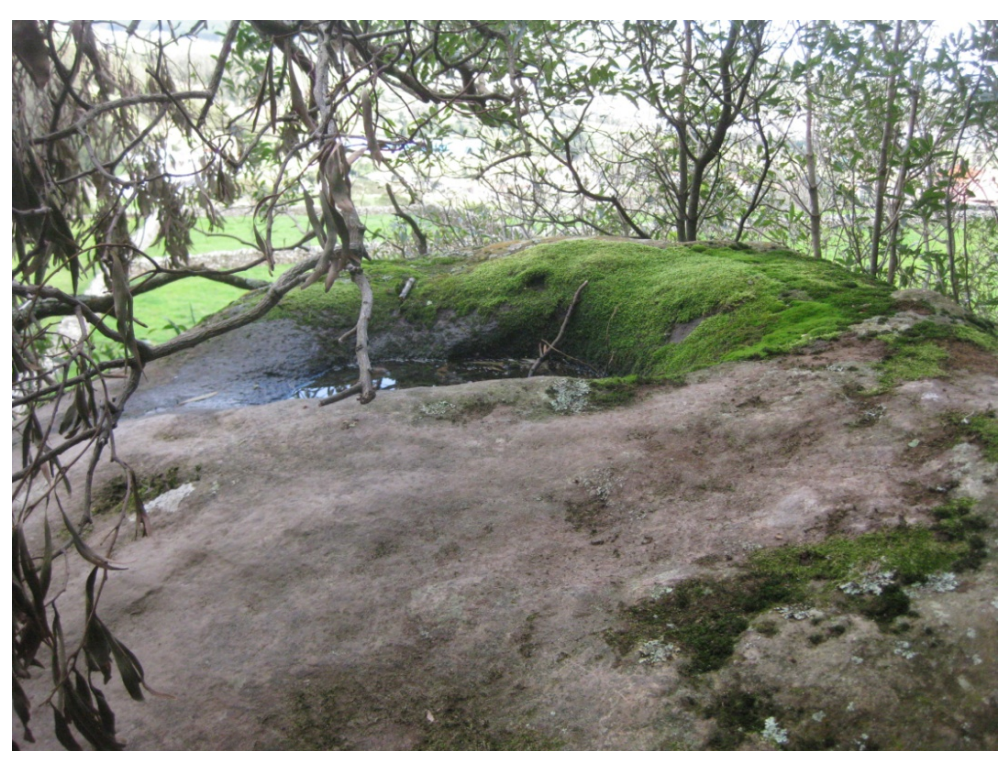

Figure 3. Bowl on the capstone of a megalithic structure alike to an Irish Wedge-shaped gallery grave.

At Grota do Medo site, almost all of these landscape elements are present: from the hill we can perceive the sea, watercourses, outcrops and the highest mountain of the island.

The bullauns are the term used for the depression in a stone which is often water filled in Ireland. Bullauns stones are not unique to Ireland and Scotland, being also found on the Swedish island of Gotland, and in Lithuania and France (Dolan, 2009).

The depressions in a stone (bullaun) is possibly enlarged from already-existing solution-pits caused by rain (Dolan, 2009), and being a reminiscence of the cup-marked stones which occur all over Atlantic Europe, and their sense (if not their precise use) probably date from Neolithic times (Cummings, 2001).

More than twenty stones with carved bowls where found in Grota do Medo site. Most of these bowls are located in improper places for animal or human uses. Usually the bowls are carved on the top of the cliff.

The size of the bowls is highly variable and these hemispherical or square cups hollowed out of a rock may come as singles or multiples with the same rock (see Figure 4).

Dolan (2009) says that the Irish bullauns had a consistent association with early ecclesiastical sites, which made some investigators to date them from the early medieval period, but the crucial issue in the study of the Irish bullauns stones, has been the unverifiable nature of the most popular theories about their use.

The bowls found at Terceira Island, with similarities with the Irish bullauns, are not associated with ecclesiastical sites, and some of them, located in the top of cliffs, clearly show that they are not used for processing grain or another known agricultural product.

Dolan (2009) argue that the term bullaun, used by the Irish archaeologists are not shown to be clearly prehistoric or natural, and when incorporated in monuments do not share a single chronology or function. The origin or function of the Iris bullauns cannot be transposed to the Terceira Island bowls, because they are combined with rock art. For example, also in the capstone of the monolithic resembling a Wedge-shaped gallery grave at Terceira Island (Figure 3), it was found an engraving similar to a Scandinavia Bronze Age boat (see Figure 5).

For further comparison of the engrave from Figure 5 with the rock art chronology of boat images in southern Scandinavia see, for example, Goldhahn \& Fuglestvedt (2012).

Coles (2000) has studied more than 10.000 boat images in the Bohüslan/Vestfold region (Scandinavia) and suggests that the journeys in the Bronze Age, undertaken by boats, were of great significance and required some sort of commemoration, materially represented in rock carvings.

The megalithic structure from Terceira Island, similar to an Irish wedge tomb with a hypothetical Scandinavian boat engrave is, at least, enigmatic. It is known that the majority of the Ireland wedge tombs date to the Early Bronze Age. Based on the evidence from Irish exhumed wedge tombs, recent research has confirmed that they appear quite abruptly, shortly after c. 2500 BC. The most debated cause of the unexpected appearance of 


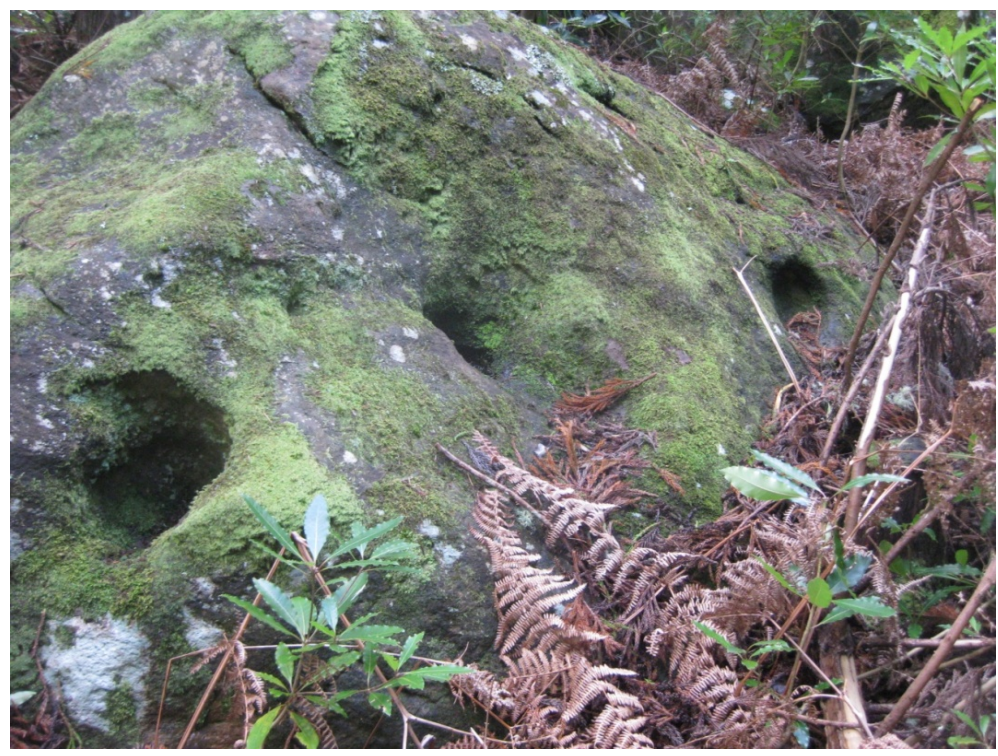

Figure 4. Multiple bowls in the same stone as mentioned by Nigel (2000) for the Irish bullauns found.

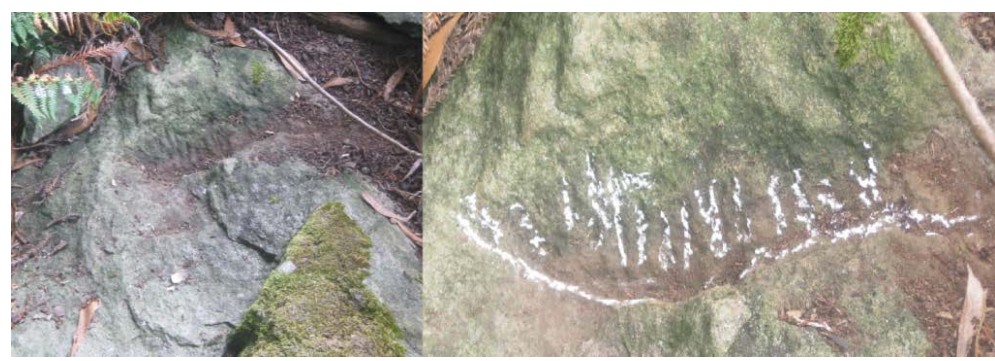

Figure 5. Engraving in the capstone with a bowl in their top, at a megalithic construction (Figure 3 ) similar to an Irish wedge-shaped gallery grave found at Terceira Island.

wedge tombs at Ireland is that of migration (Schulting et al., 2008).

Once more, the megalithic constructions, bowls and engravings at Grota do Medo site, at Terceira Island, directs us to a human pre-Portuguese presence in the Azores, before 1427, when the Archipelago was discovered.

\section{Structures Similar to Irish Portal Tombs at Grota Do Medo Site}

Four structures at Terceira Island that resemble the Irish Portal Tombs were also found, with an open east-facing entrance which leads into a rectangular or trapezoidal chamber. These chambers are roofed by a process that resembles corbelling. Surrounding the founded chambers was seeing low dry stone walls with orthostats at the extremities (see Figure 6).

The hypothetical Portal Tomb of the Figure 6 is over $1.5 \mathrm{~m}$ high and each capstone (two) is over $3 \mathrm{~m}$ in length with an angle near $90^{\circ}$ between the two capstones. It stills a mystery as to exactly how stones of this size were put in place, but it is assumed that they were pulled by men, when we study their physical equilibrium and rock art.

This megalithic structure is located at an oval or semicircular open space, like the Irish Portal Tombs, in the highest point of the Espigão Hill. It is surrounded by medium size rock, forming a kind of wall and by stairs to facilitate the capstones access.

Portal tombs receive their name from the portal stones on which one end of the large capstone of the tomb rests and they are generally associated with water (Jones, 2007). The hypothetical Portal Tomb at Terceira Island does not have all the elements mentioned by Jones (2007). 


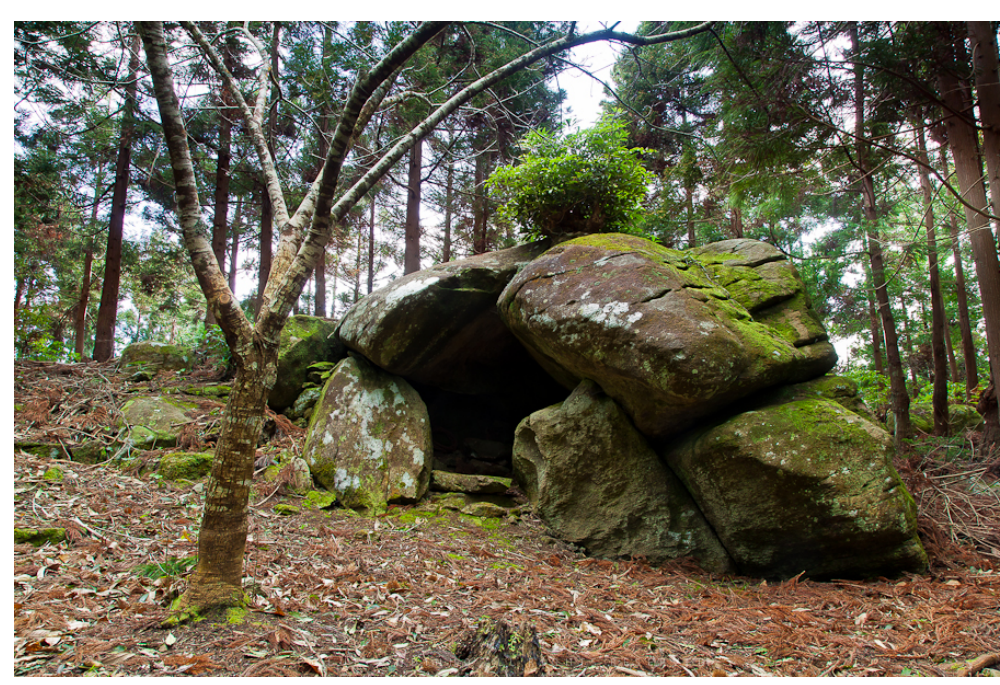

Figure 6. Megalithic structure with similarities with Portal Tombs.

Kytmannow (2008) points out a number of features that are almost always present at the location of portal tombs: "... a stream parallel to the tomb, a higher point, a slope towards the stream, and an obscured view to one side". She also states that most tombs were close to fresh water. Some of these features mentioned above are present at the site of the hypothetical Portal Tomb of Grota do Medo. In the past a stream, parallel to the tomb was present until their catchment for water consumption in Angra do Heroísmo. In front of the hypothetical Portal Tomb it is observed a quarried bowl, in a monolithic, from which water runsdown to a slope. The Terceira Island hypothetical Portal Tomb is located at the higher point of the Espigão Hill. None hidden view is present.

It is impossible at the moment explain how people built, on the island, a structure similar to a Portal Tomb at the top of the Espigão Hill. The monolith's arrangement of this structure is not explained with any kind of geological phenomenon.

\section{Rock Art}

\subsection{Similarities between "Cup-Marks" in the Azores and European Neolithic "Cup-Marks"}

Holtorf (1998), in a paper that discusses the life-histories of megaliths, writes that objects are "... made somewhere; they often do something, and some are moved from place to place...", which means that their meanings and functions can change in different contexts, different environments or different cultures.

It is known that many megaliths were preserved as they were adapted to new uses, and because of it, they were not destroyed. The megalithic structures in Terceira Island appear to be adapted, along the time, to others uses, such as romantic purpose or unknown religious practices, for example.

Holtorf (1998) studied sixty-one megaliths constructions in Germany, and concludes that $71 \%$ of all of them have cup-marks incorporated. This author states that they are expressions of history and culture.

Grota do Medo cup-marks and cut-marks are present in hundreds of big stones, and sometimes combined like pointing to produce art.

The cup-marks found are simple, roughly hemispherical depressions from about $2 \mathrm{~cm}$ to $10 \mathrm{~cm}$ of diameter and from $1 \mathrm{~cm}$ to $3 \mathrm{~cm}$ depth on the surface of many monolithic blocks (see Figure 7). Cup-marks often appear in group which can consist in more than one hundred marks on a single stone. Clear similarities were found with those ones created in Stone Circles in Scotland or in other megalithic places in Spain and Portugal, as mentioned above (see Bradley et al., 1995).

Cup-marks are usually a form of prehistoric art found mainly in Atlantic Europe (Northern England, Scotland, Ireland, Brittany, Portugal, Spain and Mediterranean Europe (Bradley et al., 1995)).

In Terceira Island, cup-marks are abundant and found near the large constructions or disperse on a number of disconnected cup-marked stones.

Cup-marks are among the most enigmatic aspects of Bronze Age religion be it sun worship or associated with 


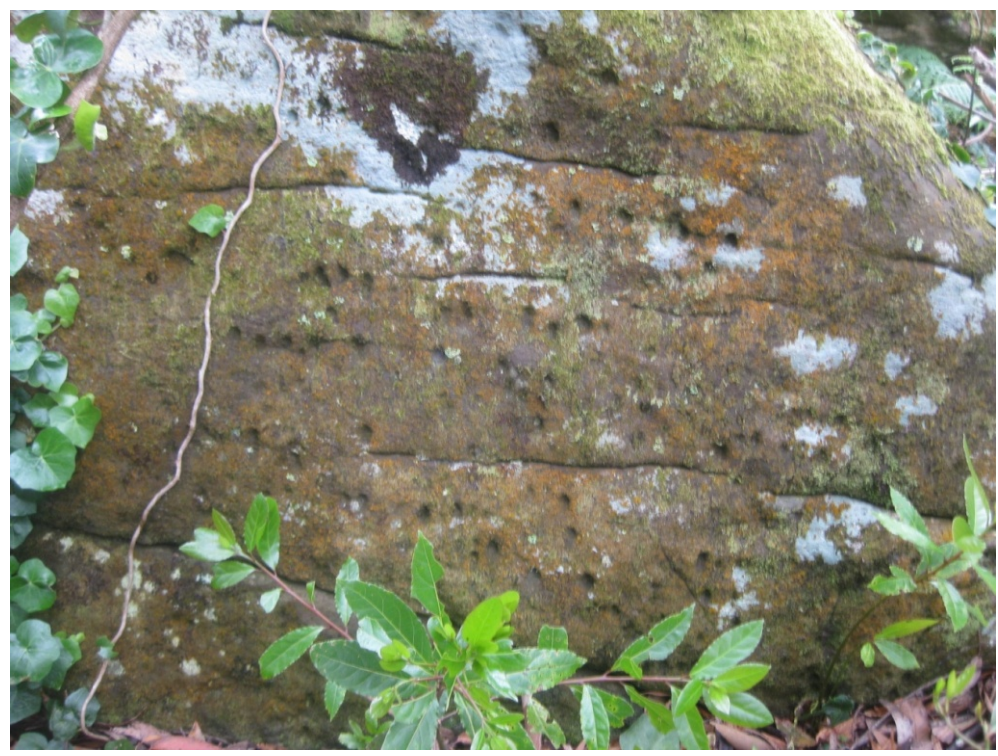

Figure 7. Trachyte (igneous volcanic rock) with typical cup-marks at Grota do Medo site.

others forms of astronomical observation, as stated by Ritchie \& Ritchie (2003).

The cup-marked decorated stones, found in Terceira Island, and their enigmatic meaning, points toward a human pre-Portuguese presence in the Azores, or to a cultural phenomenon not described or not identified in the ethnography of the Portuguese people from the XVth century.

\subsection{Similarities between Rock Art in the Azores and European Copper Age Culture}

It was found at the Grota do Medo area a series of inscriptions with abstract schemes, ranging from simples dots or cup-marks as illustrated above, lined cut-marks to more complex motifs. The chronology of these draws or even of the megalithic constructions remains to be resolved but they have, once again, similarities with some late European Neolithic rock art.

The Atlantic style rock art extends from northern Portugal to the north of the British Isles, with practically identical geometrical designs found: circular combinations, spirals and labyrinth shapes, amongst others (Ritchie \& Ritchie, 2003). At Grota do Medo site no spirals or labyrinth shapes were found.

One circular inscription was found and several semi-circular inscriptions, but the most numerous draws seem, at the moment, inexplicable. We believe that part of the Grota do Medo Rock Art could be included in its one iconic base, because many symbols have only a formal similarity to those ones from the Neolithic (see Figure 8 and Figure 9).

The example of Figure 9 has indubitable similarities with the Tablero de juego ajedrezado from Santa Trega or the Santa Maria de Taboexa, in Galicia-Spain (see Garcia et al., 1999).

The petroglyphs with crossed lines in the form of chess game have been linked to the Copper Age culture (Garcia et al., 1999).

Dozens of single blocks with engravings were found in the Grota do Medo site, some combining cup-marks with cut-marks (see Figure 8), and others combining cut-marks with cup-marks and vertical lines in mimeoliths (rocks and stones that imitate living beings).

The megalithic builders employed the same method of splitting stones, at different locations all around the world, using cut-marks. This is not unusual, and it is probably the best method to split monolithic blocks, and it is still widely used today.

The shape of the cut-marks at Terceira Island and their volume has similarities with cut-marks from megalithic quarries in France, Ireland, Portugal and Malta.

No historical quarry was registered for Grota do Medo site. Numerous stones with cup-marks that seem to anthropomorphize or animalize the stones were found at Terceira Island. Usually the cut-marks appear to be the eyes of a person or an animal. 


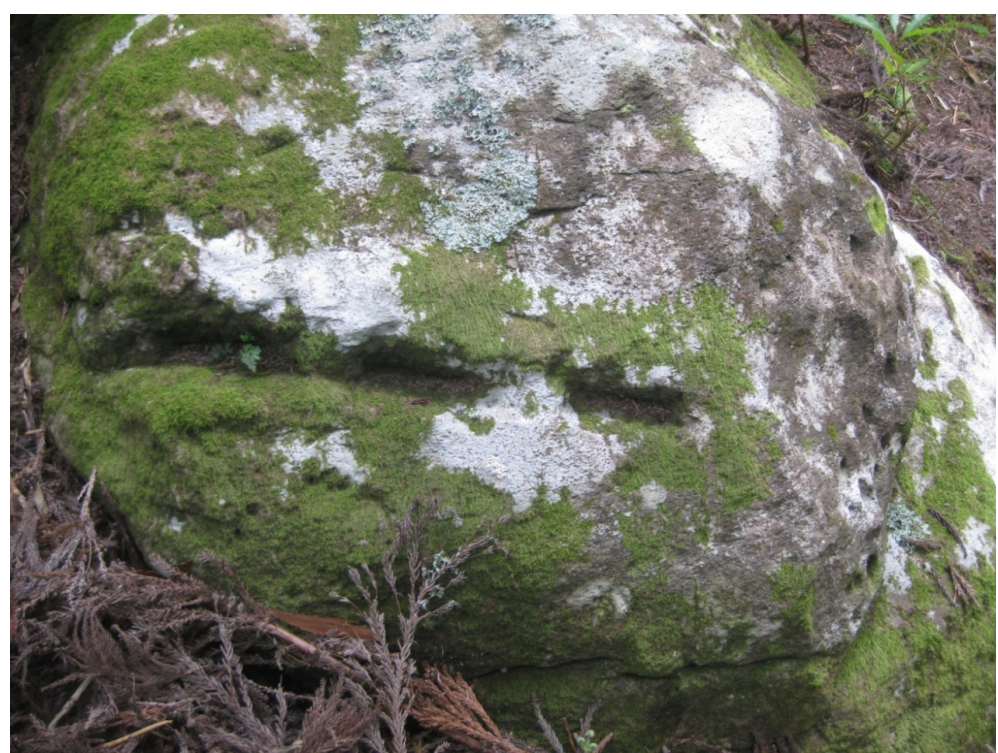

Figure 8. Example of a stone with cut-marks in front, cup-marks in the right side and a drawing in the top (not visible in the image).

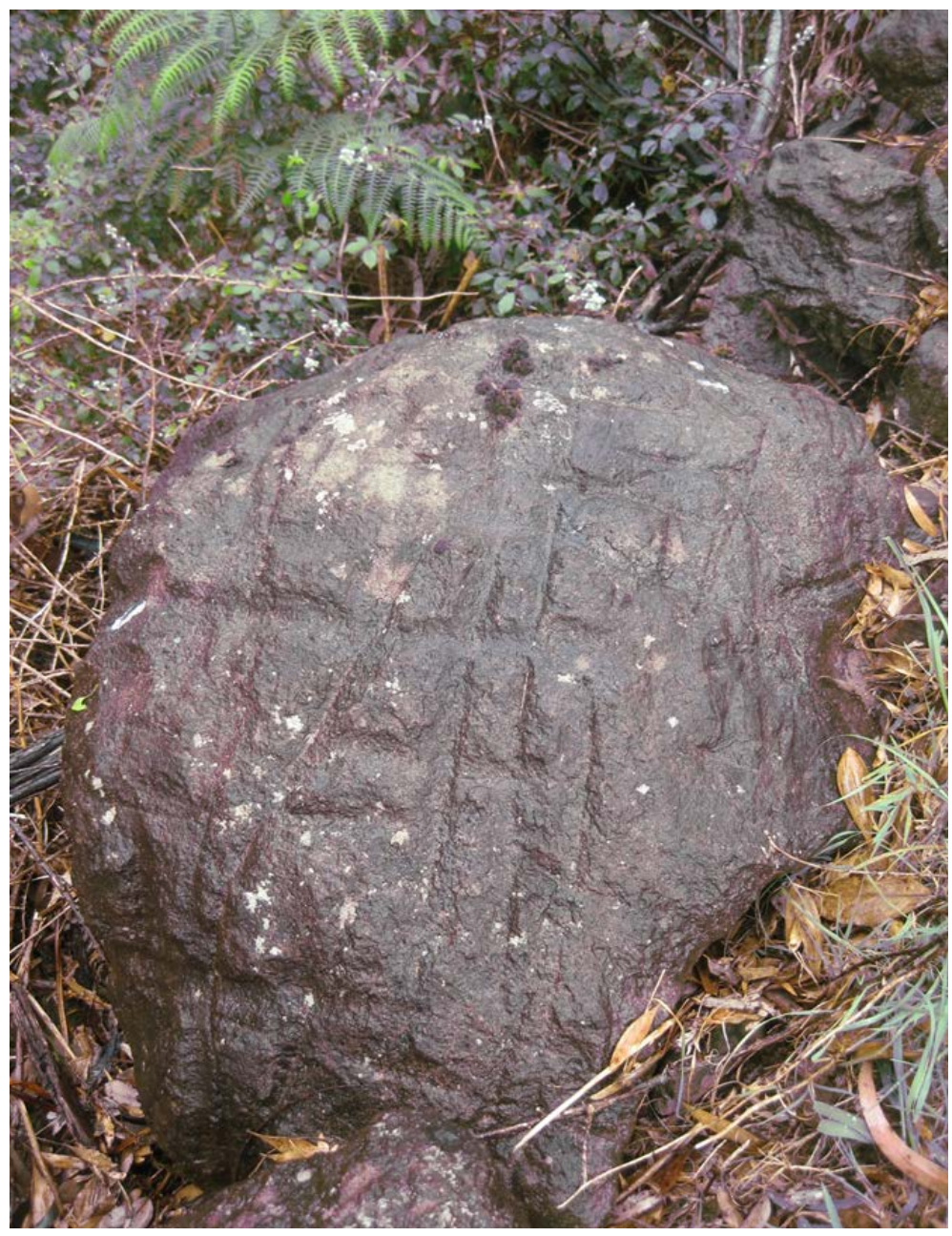

Figure 9. Another example of Rock Art at Grota do Medo site. 
If the studied place was a quarry, no stones were removed from there to build walls or modern houses nearby. The rock art at Grota do Medo site remains still unexplained by the local ethnography.

\section{Conclusion}

This work, based on a comparative analysis, represents an approach in the range of scientific research methods, and in some ways, it is a mix of other methods, like the ones used in physics and geology. It was assumed that the simple comparison of two objects, one from the Terceira Island and the other from an European Neolithic site, was not a comparative research, but a substantial number of coincidences could reinforce the hypothesis of a human pre-Portuguese presence in the Azores in the ancient times. The absence of documents or historical reference to the megalithic constructions at Terceira Island requires this starting assumption and also a first fleeting look of the cultural landscape present at Grota do Medo site.

A new kind of work needs to be made at Grota do Medo site with the rigorous use of the scientific method and with a multidisciplinary team in order to get archaeological artifacts or other kinds of dating materials. This will reveal more about the needs of the local communities who built and use such structures or use this peculiar landscape.

\section{Acknowledgements}

The authors warmly thank three anonymous referees for their suggestions that improved the quality of the original manuscript. The authors are also grateful to Nuno Martins for his support.

\section{References}

Barker, C. T. (1992). The Chambered Tombs of South-West Wales: A Re-Assessment of the Neolithic Burial Monuments of Carmarthenshire and Pembrokeshire (p. 4). Oxford: Oxbow Monograph.

Bradley, R. (1997). Rock Art and the Prehistory of Atlantic Europe. London: Routledge.

Bradley, R., Criado, F., \& Fábregas, R. (1995). Rock Art and the Prehistoric Landscape of Galicia: The Results of Field Survey 1992-1994. Proceedings of the Prehistoric Society, 61, 347-370. http://dx.doi.org/10.1017/S0079497X00003121

Brennan, M. (1983). The Stars and the Stones. London: Thames and Hudson.

Carter, T. (2014). Ch. 1.2: The Contribution of Obsidian Characterization Studies to Early Prehistoric Archaeology. Etudes et Recherches Archéologiques del'Université de Liège (ERAUL), 138, 23-33.

Cauvin, J. (2000). The Birth of the Gods and the Origins of Agriculture. Cambridge: Cambridge University Press.

Cauvin, M. C., Gourgaud, A., Gratauze, B., Arnaud, N., Poupeau, G., Poidevin, J. L. \& Chataigner, C. (Eds.) (1998). L'Obsidienne au Proche et Moyen Orient: Du volcan à l'outil. Maison de l'Orient Méditerranéen. Oxford: Archaeopress, BAR International Series 738.

Clark, P. (2004). The Dover Bronze Age Boat, with Illustrations by Caroline Caldwell. London: English Heritage.

Coles, J. (2000). Patterns in a Rocky Land: Rock Carvings in South-West Uppland, Sweden, Volume 1. Uppsala: Department of Archaeology and Ancient History.

Contu, E. (2000). L’Altare preistorico di Monte D’Accoddi. Sardegna Archeologica, 29. Sassari. Carlo Delfino editore. Italia.

Cummings, V. (2001). Landscapes in Transition? Exploring the Origins of Monumentality in South-West Wales and SouthWest Scotland. Ph.D. Thesis, Cardiff: Cardiff University.

Cunliffe, B. (2001). Facing the Ocean: The Atlantic and Its Peoples, 8000 BC to AD 1500. Oxford: Oxford University Press.

Cunliffe, B. (2009). Iron Age Communities in Britain (4th ed.). London: Routledge.

Daniel, G. E. (1950). The Prehistoric Chambered Tombs of England and Wales, Cambridge. Cambridge: Cambridge University Press.

Dolan, B. (2009). Bedrocks and Bullauns: More than One Use for a Mortar? Archaeology Ireland, 23, 16-19.

Fowler, C., \& Cummings, V. (2003). Places of Transformation: Building Monuments from Water and Stone in the Neolithic of the Irish Sea. Journal of the Royal Anthropological Institute, 9, 1-20. http://dx.doi.org/10.1111/1467-9655.t01-3-00001

Garcia, E., Goberna, F., \& Cuñarro, J. (1999). Petroglifos en los Castros Gallegos. Revista de Guimarães, Volume Especial, 2, 793-818.

Goldhahn, J., \& Fuglestvedt, I. (2012). Ch. 4: Engendering North European Rock Art: Bodies and Cosmologies in Stone and 
Bronze Age Imagery. In A Companion to Rock Art (pp. 237-260). Oxford: Blackwell Publishing Ltd.

Holtorf, C. (1998). The Life-Histories of Megaliths in Mecklenburg-Vorpommern (Germany). World Archaeology, 30, $23-38$. http://dx.doi.org/10.1080/00438243.1998.9980395

Johnson, W. (1908). The Later History of the Megaliths: One Chapter of "Folk Memory". Paperback-Facsimile, February 1991. Avebury: Heart of Albion Press.

Jones, C. (2007). Temples of Stone: Exploring the Megalithic Tombs of Ireland. Cork: The Collins Press.

Knight, P. (2011). West Kennet Long Barrow. Calne: Landscape, Shamans and the Cosmos Stone Seeker Publishing.

Kytmannow, T. (2008). Portal Tombs in the Landscape: The Chronology, Morphology and Landscape Setting of the Portal Tombs of Ireland, Wales and Cornwall. BAR British Series 455, Oxford: Archaeopress.

Needham, S. (1985). Neolithic and Bronze Age Settlement on the Buried Floodplains of Runnymede. Oxford Journal of Archaeology, 4, 125-137. http://dx.doi.org/10.1111/j.1468-0092.1985.tb00237.x

Nigel, G. (2000). Ch. 5: The Quick and the Dead: The Social Context of Aceramic Neolithic Mortuary Practices as Seen from Kfar Hahoresh. In Life in Neolithic Farming Communities. Social Organization, Identity, and Differentiation (pp. 103-136). New York: Kluwer Academic Publishers.

Ó Nualláin, S., \& De Valera, R. (1961). Survey of the Megalithic Tombs of Ireland. Dublin: Ordnance Survey Ireland.

O’Sullivan, M. (1988). Approaches to Passage-Tomb Art. Journal of the Royal Society of Antiquaries of Ireland, 116, 68-83.

Ritchie, G., \& Ritchie, A. (2003). Scotland: Archaeology and Early History (2nd ed.). Edinburgh: Edinburgh University Press.

Schulting, R., Sheridan, A., Clarke, S., \& Ramsey, C. B. (2008). Largantea and the Dating of Irish Wedge Tombs. The Journal of Irish Archaeology, 17, 1-17.

Sheridan, J. A. (2010). Ch. 9: The Neolithization of Britain and Ireland: The "Big Picture". In Landscapes in Transition (pp 89-105). Oxford: Oxbow/Council for British Research in the Levant, Levant Supplementary Series 8.

Van de Noort, R. (2009). Ch. 11: Exploring the Ritual of Travel in Prehistoric Europe: The Bronze Age Sewn-Plank Boats in Context. In Bronze Age Connections: Cultural Contact in Prehistoric Europe (pp. 159-175). Oxford: Oxbow Books. 